\title{
Andrew Jackson y la causa texana
}

\author{
Pedro Fernando Castro Martinez \\ UAM-IZTAPALAPA
}

\author{
Análisis de la intervención del presidente de Estados \\ Unidos, Andrew Jackson, en el proceso que condujo a la \\ separación de Texas de la república mexicana.
}

$A$ ndrew Jackson, séptimo presidente de Estados Unidos, es sin duda una de las mayores figuras míticas de la historia norteamericana. Aclamado como héroe por sus hazañas militares, este abogado autodidacta pasó a ser destacado personaje político entre los gobiernos de Thomas Jefferson y Abraham Lincoln. Fue el primer presidente nacido al oeste de los Apalaches, y su ascenso al poder se mostró durante muchos años como un ejemplo de las bondades que la democracia estadunidense ofrecía a quienes, sin importar sus orígenes, les sobraba ambición y perseverancia. Por si fuera poco, la historia personal de Jackson, sus convicciones e ideales, su espíritu fronterizo, lo convirtieron en campeón del expansionismo norteamericano y eminencia gris de la incorporación de Texas a la Unión Americana.

El crecimiento territorial de Estados Unidos, durante la llamada "Era de Jackson" (1829-37), era un fenómeno a todas luces irresistible. Movimientos sucesivos hacia el oeste acortaban la distancia entre las fronteras móviles y el océano Pacifi$c o$, de tal modo que la continentalización del país era cuestión de tiempo. Este impulso se veía favorecido por varias circunstancias. El insaciable apetito norteamericano por suelos abundantes, fértiles y baratos, hizo del oeste un punto menos que la tierra prometida. En muchos existía la creencia de que los bue- 
nos espacios para la agricultura se agotaban sin remedio, y de que las repetidas crisis económicas -la de 1837, por ejemplo- no deparaban ningún futuro de prosperidad para ellos y sus familias. Granjeros arruinados tomaban los caminos hacia Texas, Oregon o California, en busca de nuevos horizontes.

Andrew Jackson compartia con muchos de sus contemporáneos una idea de la grandeza de su patria y una obsesión sin límites por los territorios de sus vecinos -españoles y luego mexicanos- del oeste. Desde su juventud, quien también fue conocido con el sobrenombre de Old Hickory (Viejo Roble), estaba seguro de que algún día los dominios de Estados Unidos se extenderían hasta el océano Pacífico. Característica invariable de su pensamiento y acción en este sentido fue su constancia mostrada en realizar sus sueños. Texas, California, algún día serían norteamericanos.

Andrew Jackson fue elegido mayor general de la milicia de Tennessee en 1802. Su vida militar aquí seguramente hubiera carecido de interés a no ser por la aparición de un personaje de novela llamado Aaron Burr. Con ingenuidad o sin ella; el caso es que al Viejo Roble lo atrajeron sus peregrinos proyectos, que los libros de historia llamarian la Conspiración de Burr de 1805-06. Tales intenciones compartidas siguen hasta hoy envueltas en el misterio; sus pormenores son confusos al igual que sus motivos.

Aaron Burr, vicepresidente de Estados Unidos durante los primeros tres años del periodo de Thomas Jefferson (1801-1809), buscaba una alternativa después de haberse desplomado politicamente a resultas de haber matado a Alexander Hamilton en un duelo. Marginado de los negocios públicos por sus antiguos compañeros jeffersonianos, Burr emprendió su marcha personal al oeste.
Partía de que una guerra con España era inminente, y de que esta coyuntura favorecía la organización de un ejército que descendiera sobre México. En general, las empresas invasoras contra las colonias españolas despertaban reacciones favorables entre los rudos habitantes de la frontera norteamericana. Andrew Jackson, como muchos, fue atraído por la posibilidad de conquistar al imperio hispano de América y así ganar tierras ricas y poco pobladas. El mismo Viejo Roble deseaba ponerse a la cabeza de los voluntarios de Tennessee, y con este fin lanzó una proclama en la que denunciaba que los españoles "estaban acampados dentro de los límites de nuestro territorio", y pedía a la tropa que estuviera lista para cumplir con su deber. Jackson fue más allá: proporcionó a Burr una lista con nombres de oficiales de confianza y dos barcazas. Sin embargo, cuando tomó conciencia de los peligros que encerraban los planes de Burr para su futuro, el Viejo Roble optó por desligarse de la aventura. Aparentemente cayó en la cuenta de que el ex político buscaba separar a los estados fronterizos de la Unión con apoyo de la Gran Bretaña, absorber Nueva España, y hasta convertirse en "emperador" de México. ${ }^{1}$ A la postre, Burr acabaría abandonando tantas quimeras, y luego huiría a España, donde moriría pobre y olvidado.

Andrew Jackson tuvo una nueva oportunidad de participar, de manera secundaria, en el proceso de expansión ternitorial de Estados Unidos. En virtud. del Tratado con España de 1819, Washington renunciaba a sus reclamaciones sobre Texas-según él, era parte integral de Luisiana-, a cambio de asegurarse la Florida. Este acuerdo, conocido como

${ }^{1}$ Padover, Jefferson, 1969 , p. 194; Daniels, Ordeal, 1976, pp. 184-187. 


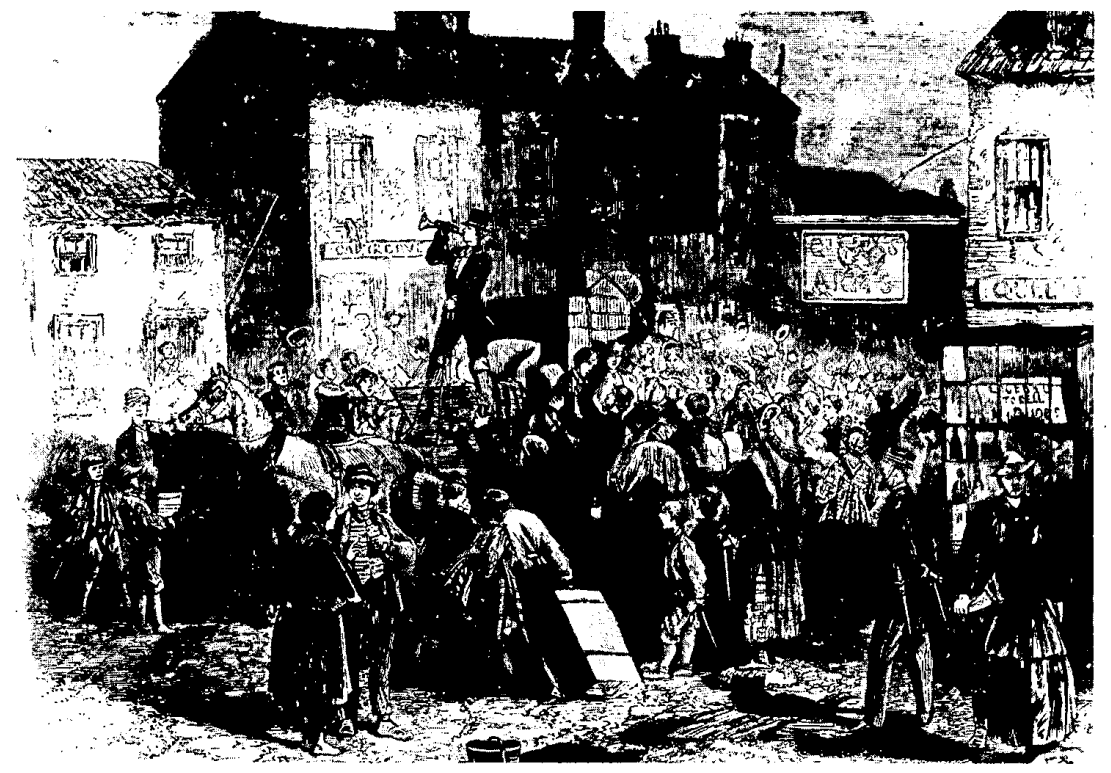

Tratado Onís-Adams (1819), fue un triunfo redondo para Estados Unidos, porque España le cedió el este de Florida, reconoció su ocupación de la Florida occidental (llevada a cabo por el mismo Jackson), y le cedió sus derechos a los territorios al noroeste de la misma sobre el paralelo 42. A cambio, Washington renunció a sus fantasiosas demandas sobre Texas y asumió el pago de las reclamaciones de sus ciudadanos afectados en la Nueva España hasta la suma de 5000000 de dólares. ${ }^{2}$ Al parecer, Andrew Jackson estuvo de acuerdo con el tratado, porque en ese tiempo el asunto de Florida era más apremiante que el de Texas. Éste podía esperar, y esperaría.

${ }^{2}$ Moyano, Origen, 1987, p. 39; Merk, Manifest, 1963, p. 15.
La administración de John Quincy Adams envió a México (ya un país independiente) en 1822 al célebre Joel Poinsett, quien tenía la tarea de lograr la firma de un tratado comercial entre los dos países. También el ministro Poinsett trataría de conseguir que la nueva república de México aceptase al río Bravo, o a algún otro punto al sur del río Sabina, como límite internacional. México interpretó esta intención como una prueba de que Estados Unidos pretendía abusar de su debilidad y se resistió con firmeza a aceptar las propuestas norteamericanas. Poinsett fue entonces instruido para que ofreciera 1000000 de dólares a los mexicanos a cambio de Texas, pero no se atrevió a seguir adelante para no empeorar las relaciones entre su país y sus anfitriones. A lo más, concluyó un tratado comercial en 1828 , que declaraba al 
río Sabina como frontera entre las dos naciones.

Una vez en la presidencia de la república, Andrew Jackson se dispuso a sacar adelante sus proyectos para que Texas formase parte de la Unión Americana. Hizo todo lo posible por impedir o al menos retrasar la ratificación del tratado promovido por Poinsett. ${ }^{3}$ En cambio decidió reabrir negociaciones para la compra de Texas. Expresó en forma confidencial a su secretario de Estado, Van Buren que 2000000 de dólares servirían para modificar la Constitución mexicana para que así fuera posible la venta de esa parte de su territorio, y hasta estaba dispuesto a dar 5000000 de dólares para conseguir Texas "hasta las Grandes Praderas o el desierto". Pensaba que Estados Unidos debía tener esa región para impedir que una "potencia extranjera" tuviese acceso a los tributarios del Mississippi, ya que "el Dios del universo ha dispuesto que este gran valle pertenezca a una sola nación".

De acuerdo con tales propósitos, en agosto de 1829 Jackson firmó las instrucciones para Joel Poinsett. En ellas se ponían de manifiesto las "ventajas" para México si vendia Texas a Estados Unidos: la frontera entre las dos naciones sería "natural" (al parecer, el Viejo Roble pensaba en el río Bravo); el dinero obtenido serviría para enfrentar una guerra probable con España; desaparecerían los riesgos de un conflicto entre los ciudadanos de los dos países vecinos; ya no habría la necesidad de lidiar con los inquietos colonos texanos; y finalmente, la enajenación de territorio sería una prueba

${ }^{3} \mathrm{~A}$ la postre se confirmaría en el tratado comercial firmado por Poinsett en $1828 \mathrm{y}$, en un acuerdo separado, se aceptaría la frontera de 1819 . Ambos fueron ratificados y promulgados por el gobierno estadunidense en 1832. Bassett, Life, 1967, p. 675.

${ }^{4}$ Ibid., p. 673. de "estimación hacia una república hermana", que le haría "merecedor de ese espíritu recíproco de amistad que siempre debe caracterizar los sentimientos mutuos de los dos gobiernos". Desde el lado de las ventajas para Estados Unidos, éstas serían "la seguridad de Nueva Orleans y el valle del Mississippi"; la adquisición de nuevos territorios para asentar a los indios desplazados del este, y también la adquisición de una "frontera natural". Jackson pensaba que la mitad del "Gran Desierto Americano" podría ser una posible frontera, y de ser obtenida podrían pagarse hasta 5000000 de dólares. ${ }^{5}$ Poinsett, sin embargo, estaba maniatado para actuar a sus anchas en un asunto de tal delicadeza. Desde los principios de su desempeño Poinsett era una persona non grata para una facción poderosa de la elite política mexicana, y estaba visto como un intrigante que pretendía dividir al país y desmembrar su territorio. Cuando dejó de ser útil, una vez que el gobierno de México solicitó el término de su misión, el presidente Jackson decidió llamarlo a Washington a fin de no empeorar sus relaciones con la república del sur. Joel Poinsett se despidió de México en diciembre de 1829.

El reemplazo de Poinsett por el coronel Anthony Butler, un camarada de las épocas militares de Jackson, probó ser una elección poco afortunada. Este personaje, en quien se combinaba una singular torpeza con un expediente ético nada recomendable, había sido investido de poderes discrecionales para poner en marcha una temprana diplomacia del dólar. Abundando en datos de su perfil, conviene decirque Butler era especulador con fuertes intereses en Texas, lo que al parecer lo hacía un embajador idóneo de

$$
\text { sIbid., p. } 674 .
$$


la causa expansionista. ${ }^{6}$ Así, en enero de 1830 llegaba a la capital mexicana un personaje que quedaría en la memoria histórica por sus torpezas y fracasos diplomáticos.

Butler tenía instrucciones terminantes de Jackson de comprar el territorio texano, pero sus anfitriones querian no más que un acuerdo sobre la frontera precisa entre México y Estados Unidos. Haciendo gala de prepotencia, Butler puso como condición a los mexicanos para resolver el asunto de límites, que se "solucionara" primero el de la venta de Texas. Una y otra vez el enviado norteamericano trató de convencer a sus obstinados interlocutores de que transfirieran su provincia septentrional, pero todo lo que sacaba era un creciente enojo y desconfianza. La hipocresía de Washington se ponía de manifiesto cuando buscaba un "arreglo diplomático" al tiempo que alentaba la emigración de colonos de su país hacia Texas. Conforme pasaba el tiempo, a Butler se le iba acabando la paciencia, pero no cesaba de dar seguridades a su jefe de que las cosas a la postre saldrian bien. Pero Butler fallaba una y otra vez. Frustrado e irritado, llegó a recomendar una "solución final": que Estados Unidos ocupase el territorio "al oeste del Sabina"?

Al ser patente el rechazo de los mexicanos a las "ofertas" de Butler, éste optó por utilizar medios menos ortodoxos. Antes comunicó a Jackson un plan para pagar 5000000 de dólares, parte a México, y parte a aventureros que habían adquirido grandes concesiones de tierras en México. El presidente Jackson le contestó que no sujetaría un asunto

6 Un cuadro completo de las actividades de Butler se encuentra en Moyano, Origen, 1987, pp. 59-63.

${ }^{7}$ Remini, Jackson, 1976, p. 353. tan delicado como el de Texas a ninguna concesión, excepto a la de Stephen Austin, y que el dinero sería pagado a México sin importar su destino posterior, pero que Butler debía tener el mayor cuidado de evitar cualquier "imputación de corrupción". ${ }^{8}$ Sin embargo, antes de la partida del representante estadunidense a México, Jackson le había insinuado la conveniencia de hacer uso de la corrupción para el logro de sus fines. Teniendo en mente a la Florida, el Viejo Roble afirmaría que apenas conocía a un español "que no sea esclavo de la avaricia, y noes improbable que esta flaqueza pueda ser de gran utilidad para nosotros".?

Hacia 1835 Butler se dirigió de México a Washington a fin de presentar a Andrew Jackson su proyecto más reciente para adquirir el anhelado territorio texano. Llevaba con él una carta atribuida a un sacerdote apellidado Hernández, confesor de la familia de Santa Anna, en la que se afirmaba que con un cohecho de 500000 dólares en favor de varias personas se podría llevar a cabo la venta de Texas en 5000000 . Pero Andrew Jackson, con su aureola de santo, garrapateó lapidariamente en un margen de la carta: "Nada será aprobado por el Ejecutivo que ponga al gobierno bajo la más remota imputación de estar inmiscuido en corrupción o cohecho". ${ }^{10}$ Jackson conocía los límites de su pragmatismo, pues sabía lo perjudicial que era para su causa adoptar cualquier postura que pusiera su honorabilidaden tela dejuicio. Su rechazo al inmoral procedimiento no era tan tajante como se pretendía. Mantuvo a Butler en su puesto y le dio una segunda oportunidad. Una vez de vuelta en México, el representante estaduni-

\footnotetext{
${ }^{8}$ Bassett, Life, 1967, p. 675.

${ }^{9}$ Remini, Jackson, 1976, p. 534.

${ }^{10}$ Bassett, Life, 1967, p. 676.
} 
dense continuó enviando despachos carentes de sentido, hasta que fue llamado de vuelta a Washington. Para sustituirlo, el 29 de enero de 1836 fue firmado el nombramiento de Powatan Ellis, quien rápidamente se dio cuenta de la dificil situación en la capital mexicana. El nuevo representante de Estados Unidos optó por hacer de ladolos proyectossobre la compra de Texas, poniendo todo su esfuerzo en llevar adelante las reclamaciones de ciudadanos contra el gobierno de México.

Para esas fechas los acontecimientos texanos estaban en ebullición, y Ellis se limitó en cambio a presionar con demandas de reparaciones en favor de los norteamericanos afectados en sus bienes o personas durante los años que siguieron a la independencia de México. Ante las dificultades que encontró para llevar a cabo su cometido, abandonó México a fines de 1836, y nadie ocupó su puesto en los tres años que siguieron. ${ }^{11}$

Uno de los cargos más serios que sostenían los mexicanos contra el presidente Jackson en relación con Texas fue a causa de su apoyo irrestricto a los colonos rebeldes. Su deseo vehemente de adquirir esta provincia, y en particular sus vínculos más que amistosos con Samuel Houston lo hacían sospechoso ante los ojos de propios y extraños. En realidad, Houston era un viejo amigo y aliado de Jackson, y desde mucho antes de que estallara la revuelta de las colonias texanas, ya existía la preocupación compartida de actuar juntos para "liberar Texas". Al parecer, esta coincidencia se galvanizaba en la medida en que Houston ajustaba sus sueños de conquista con

"Rives, "Mexican", 1913, p. 229.

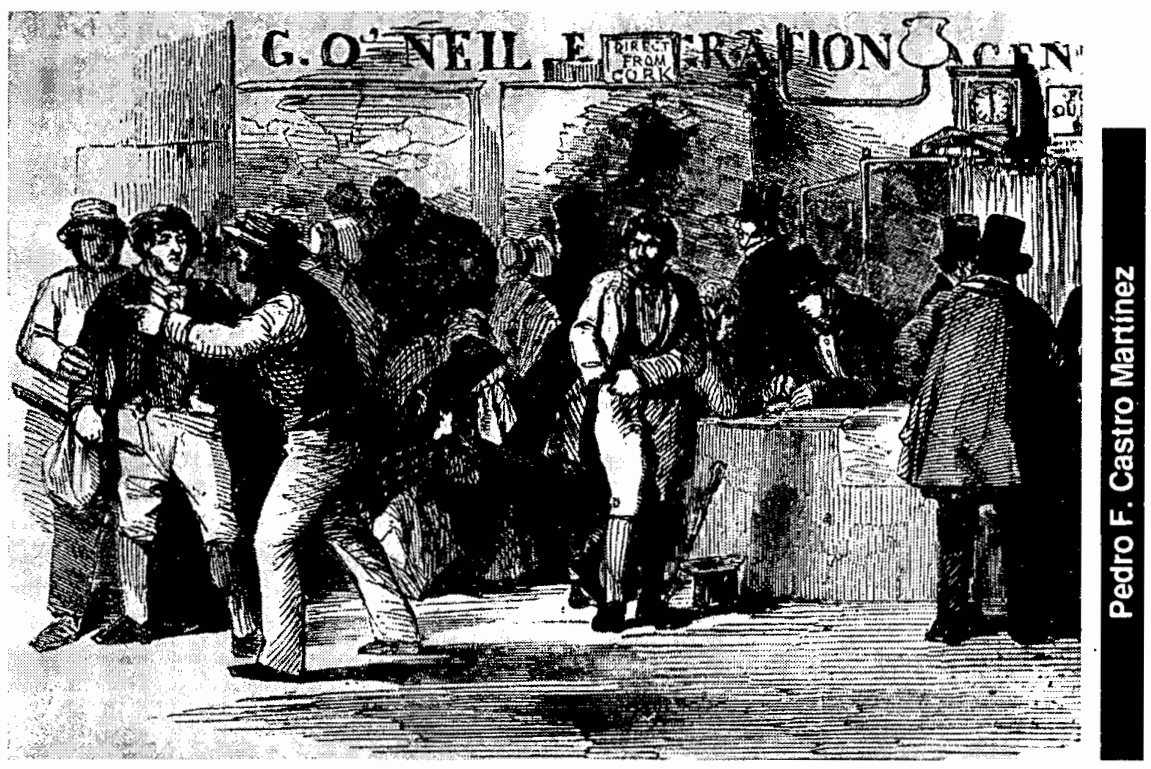


los designios de Washington. La primera evidencia documentada del asunto fue una nota escrita por mano propia de Jackson. En ella el Viejo Roble reprobaba ciertos proyectos quiméricos de Houston de invasión de Texas:

\begin{abstract}
mayo 21, 1829. [Recibí] del general Duff Green el extracto de una carta [del] doctor Marable al general $\mathrm{G}$. conteniendo declaraciones del gobernador [de Tennessee] [...] que él conquistaría México o Texas, y que costaría 2000000 en dos años \& $\mathrm{C}$. Pensé que esto serian efusiones de un cerebro perturbado, pero como medida de precaución me dirigí al secretario de Guerra para que escribiera y enviara a Mr. Poe, gobernador [sic] de Arkansas, el extracto y le instruyera que si descubría la existencia de tal proyecto adopte medidas prontas para echarlo abajo y dé al gobierno la información sobre tal empresa ilegal, con los nombres de todos los que pudieran estar implicados. ${ }^{12}$
\end{abstract}

Hay una prueba adicional que de alguna manera ligaba a Jackson y a Houston en el asunto de Texas. A fines de 1830 este último se encontraba en Washington y coincidió con el doctor Robert Mayo, a quien habló de sus planes de conquistar Texas. Mayo, a su vez, los hizo del conocimiento de Jackson en una larga carta. Cuando el presidente la leyó y dispuso su envío a William Fulton (secretario del Territorio de Arkansas), junto a otra por él escrita, en la que les señalaba que quizás la información era errónea, pero habría que estar pendiente de cualquier movimiento contra Texas. Por oscuras razones la misiva de Mayo, así como la carta a Fulton, permanecieron detenidas en el escritorio de Jackson y fueron robadas, sin que pudieran ser

\footnotetext{
${ }^{12}$ Bassett, Life, 1967, p. 677.
}

enviadas a su destinatario. Tales cartas cayeron en manos hostiles. John Quincy Adams las mostró ante la Cámara de Representantes como evidencia palpable de que Jackson respaldaba los designios conquistadores de Houston. Jackson solamente contestó que las cartas fueron robadas de los archivos federales, después de que habian llegado a su destinatario. La polémica perdió impulso ante las constantes protestas de Jackson de que la neutralidad seria mantenida. ${ }^{13}$

Jackson también buscó la comunicación directa con Houston sobre este asunto. Existe una curiosa misiva en la que el presidente le señalaba:

septiembre 28,1830 . Se me ha comunicado que usted tiene en mente la ilegal empresa de conquistar Texas; que usted ha declarado que sería, en menos de dos años, emperador de tal país por conquista. Yo pensé que usted [había] enloquecido al haber creído que usted tenía un esquema tan primitivo en perspectiva, y particularmente cuando se me ha comunicado que la fuerza física a ser empleada serían los indios cheroquis. En efecto, mi querido, señor, yo no puedo pensar que tenga tal proyecto quiméricoen mente. Su promesa de actuar en contrario es suficiente garantía de que no se comprometerá en ninguna empresa injuriosa para su país que manche su fama. ${ }^{14}$

El presidente de Estados Unidos daba señales que mostraban su doblez sobre Texas y los proyectos invasores de Houston. A los cuatro meses de que el Viejo Roble pidió a éste una "promesa de honor" de no embarcarse en una "aventura injuriosa para el país", el futuro padre de la independencia texana apareció en Washington vestido con el traje de gala

\footnotetext{
${ }^{13}$ Ibid., pp. 677-678.

14 James, Raven, 1929, p. 177.
} 
de jefe cheroqui. Para escándalo de la elegante sociedad capitalina, Jackson recibió efusivamente a su viejo amigo en la Casa Blanca. Le proporcionó ropa nueva y lo envió luego a Texas como agente confidencial del Departamento de Guerra, "para mantener conversaciones con las tribus indias a lo largo del río Rojo". Era claro que el presidente norteamericano preparaba el camuflaje para las actividades futuras de Houston en esa provincia mexicana, dado que podría ser el líder adecuado para organizar y dirigir una rebelión de los colonos. ${ }^{15}$ Así, bendecido por Jackson, Houston empezó a construir el camino que le pondría a la cabeza de la independencia texana. Se unió a la Robert Leftwich Land Grant, una sociedad de especuladores de tierras, se hizo abogado de la Galveston Bay \& Texas Land Company, y luego se puso a la cabeza de los colonos insurrectos.

Antes de que finalizara 1832, Houston se había convertido en dueño de tierras en Texas. En abril del año siguiente, fue elegido delegado por Nacogdoches en la Convención de San Felipe, cuando ésta dio la responsabilidad a Stephen Austin de lograr que Texas fuese un estado independiente de Coahuila. Después de una serie de acontecimientos que derivaron en una creciente hostilidad entre los colonos texanos y el gobierno federal, el 2 de marzo de 1836 se reunieron los delegados en Washington en el Brazos y proclamaron su independencia total de México. Houston fue elegido comandante general de un ejército improvisado, compuesto en su mayoría por hombres de la frontera. Parecía que la fortuna no les iba a sonreír: las derrotas del Álamo y Goliad apuntaban hacia el desastre. Se impuso una retirada rebelde hacia lugar

is Davis, Old, 1977 , p. 359. seguro, que era el territorio de Estados Unidos. Aprovechando un funesto descuido, Houston atacó sorpresivamente a los mexicanos que descansaban en San Jacinto y capturó a Santa Anna. Esta batalla se convirtió en decisiva, porque los texanos supieron sacar toda la ventaja al aprecio que el jalapeño tenía por su pellejo.

El presidente Jackson estuvo al tanto de los movimientos militares de Houston, y desde luego, de la persecución de los rebeldes. Cuando las noticias de la retirada texana llegaron a sus manos, trazó sobre un mapa de Texas con su dedo índice la carrera de Houston, y se detuvo en San Jacinto, cerca de la bahía de Galveston. "Este es el lugar", dijo. "Si Sam Houston vale algo, se detendrá aquí y le dará batalla." Días después el Viejo Roble recibió las increibles novedades de la victoria texana en San Jacinto el 21 de abril de 1836, la derrota completa de los mexicanos y la captura de Santa Anna. El teniente Hitchcock, su mensajero, notó la confianza nerviosa del viejo: "Ésta es su letra", decía una y otra vez. "Es la letra de Sam Houston. Lo sé muy bien. No puede haber duda de lo que dice."16 Regocijado con las buenas nuevas, Jackson se despojó de sus vestiduras de neutral. Dispuso de inmediato la liberación de fondos federales para el ejército texano y escribió a Houston: "Espero que no pueda haber más retraso o discordia en la organización de un gobierno estable para hacer uso de la independencia que usted y sus hombres han ganado tan bravamente." Pero conforme observaba que la fiebre de conquistar. México cundía por el sur y el oeste y miles de hombres se enrolaban en el ejército texano, Jackson resolvió ser más cauteloso. ${ }^{17}$

\footnotetext{
${ }^{16}$ James, Raven, 1929, pp. 261-262.

${ }^{17}$ Davis, Old, 1977, p. 360.
} 
Durante la revuelta texana Estados Unidos mantuvo oficialmente una postura acorde con la ley de Neutralidad de 1818. En apariencia, Jackson intentaba hacer valer esta neutralidad, ordenando a los fiscales de distrito de la frontera perseguir a los infractores de tal disposición, pero estas indicaciones quedaron en el papel. Era imposible detener el clamor por la independencia texana en Estados Unidos. Agentes texanos reclutaban "inmigrantes" a plena luz del día, y no ocultaban sus propósitos de engrosar las filas de los rebeldes.

La actitud intervencionista de Washington había sido evidente en los preparativos militares de apoyo a los texanos en caso de que tuvieran reveses. Alestallar el conflicto, Jackson tenía tropas estacionadas en la frontera de su país con México. El plan trazado de antemano entre Jackson y Houston consistia en que, dado el caso de mala fortuna para los rebeldes, éstos se replegaran a la zona situada entre los ríos Neches y Sabina, y así se propiciaría un enfrentamiento entre las tropas norteamericanas y las mexicanas que llevase a un conflicto internacional. Es necesario señalar que en los convenios sobre límites entre las dos naciones quedaba el río Sabina como su frontera. Sin embargo, Estados Unidos alegaba que el límite real era el río Neches. Esa posición sostenía que la precariedad de reconocimientos topográficos inducía supuestas discrepancias entre lo que se encontraba en mapas y convenios y la realidad de las cosas en el terreno. Así, en caso de que Santa Anna llegase a la inventada "zona de conflicto", una vez cruzado el río Neches, intervendría el ejército fronterizo de Estados Unidos, bajo el mando del general Gaines. ${ }^{18}$ En el

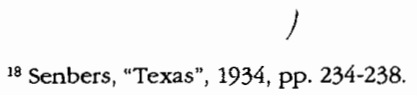

momento en que los texanos estaban capturando a Santa Anna en San Jacinto, Gaines se encontraba a la expectativa a solamente 25 millas de allí. Cuando juzgó que su presencia no era necesaria, Gaines decidió suspender sus planes de intervención.

Semanas más tarde se supo que México se estaba preparando para reanudar la lucha. Por esas fechas dos norteamericanos habían sido asesinados por indios caddo cerca de Nacogdoches, y esto se convirtió en un magnífico pretexto para que el general Gaines lanzara 200 hombres sobre esa población, en junio de 1836 . Cuando el militar se disponía a invadir, solicitó el auxilio de la milicia fronteriza. Jackson estaba en su famosa residencia del Hermitage, cuando recibió una petición en este sentido firmada por el gobernador de Tennessee. El presidente le contestó que la solicitud de Gaines era improcedente, y que no se le darían más tropas a menos que así lo dispusiera el Departamento de Guerra. El 4 de septiembre de 1836 ordenó a Gaines que "observara una estricta neutralidad", "que no incursionara en Texas a menos que los mexicanos fracasaran en detener a los indios" (Gaines ya estaba en Nacogdoches) y que "no sostuviera correspondencia con los líderes mexicanos ni con los texanos". Esta actitud de Jackson era de una doblez infinita, porque Gaines no hubiera tomado ninguna iniciativa sin su aprobación. El ministro mexicano en Washington, Eduardo de Gorostiza, no se tragaba las disculpas ni las protestas de neutralidad de Estados Unidos, así que pidió sus documentos, no $\sin$ antes denunciar la hipocresía jacksoniana en los periódicos y a la comunidad diplomática allí residente.

Desde el principio de la rebelión texana, los colonos buscaron el apoyo 
decidido de Washington con miras al futuro. Se acercaron a Jackson en busca del reconocimiento de la independencia de su país y su posterior anexión a la Unión Americana. Seis días antes de la victoria de San Jacinto, Stephen Austin envió una clamorosa solicitud a Andrew Jackson: " $\mathrm{OOh}$, paisanos míos! Los afectuosos, caballerosos, impulsivos oeste y. sur actúan en favor de Texas. El norte, más calculador y prudente, aunque no menos noble, está inquieto...¿Haría usted [Jackson] oídos sordos?"

Esta súplica llegó por carta al presidente de Estados Unidos, a su gobernante y al Congreso de la Unión. Una vez que la leyó, Jackson apuntaría en su margen:

con México, y que nuestra fe nacional debe plegarse a ello. Los texanos, antes de tomar la decisión de declararse independientes, que ha excitado y levantado a todo México contra ellos, debieron haber ponderado bien la situación. Fue un acto precipitado y prematuro; nuestra neutralidad debe ser fielmente mantenida. ${ }^{19}$

La victoria de San Jacinto cambió radicalmente la situación. El 6 de junio de 1836 la Câmara de Representantes resolvió reconocer la independencia texana "tan pronto como tuviera un gobierno establecido". Jackson, por su parte, envió un agente confidencial (de apellido Moffit) más allá del río Sabina con el fin de que se informase sobre la situación prevaleciente en Texas. Una vez que Moffit regresó de su viaje, presentó una apreciación poco favorable a los antiguos colonos. Decía que sus habitantes eran pocos y estaban demasiado dispersos, de allí su incapacidad para defenderse de nuevos ataques de los mexicanos.

El 21 de diciembre de 1836 el pre-

${ }^{19}$ Bassett, Life, 1967, p. 360. sidente Jackson, en su Mensaje al Congreso, recomendó que se mantuviera en suspenso el reconocimiento de la independencia texana. No dijo nada sobre la anexión y se limitó a declarar que: "El reconocimiento en este momento [...] no sería considerado como consistente con la prudente reserva a que estamos obligados cuando se tratan casos semejantes. ${ }^{20}$

Los texanos no se resignaron y enviaron a William $W$. Wharton como ministro de la nueva república, con instrucciones de asediar al Congreso y a la Casa Blanca. Jackson atendió a Wharton pero se rehusó a patrocinar el reconocimiento de Texas como país independiente. Éste era, dijo, responsabilidad del Congreso. Cuando Wharton recalcó que el Congreso no actuaría ante la desaprobación de Jackson en su mensaje anual, el presidente se negó a hablar más del asunto. ${ }^{21}$ En conversaciones posteriores Jackson confesó a Wharton que él esperaba, como lo había hecho durante toda su vida, que Texas fuese parte de Estados Unidos. Pero agregó que estaba decidido a que el asunto no hiciera peligrar a la Unión dando rienda suelta a los enconos seccionales: no podía tener lugar la anexión de Texas a Estados Unidos a menos que el norte y el sur se pusieran de acuerdo. Había un camino para hacer viable la anexión: los intereses del norte estaban ansiosos por tener un puerto en la costa del Pacífico, y si lo conseguían, cesarian sus protestas contra la extensión de la esclavitud en el suroeste. "Texas debe demandar las Californias". ${ }^{22}$ Esta enérgica consigna daría la dirección a los

${ }^{20}$ Ibid., p. 681.

${ }^{21}$ Davis, Old, 1977, p. 360.

22 Ibid., pp. 361-362. Sobre este punto véase Hietala, Manifest, 1985 , pp. 47-54. 
años siguientes del expansionismo de Estados Unidos.

La victoria texana de San Jacinto siguió dando ocasión a sucesos que pusieron en evidencia la mala fe e ingenuidad de Santa Anna. Al generalpresidente de México, prisionero en el rancho de Orazimba y poseído por el terror de la venganza de sus captores, se le ocurrió ni más ni menos que dirigirse a Andrew Jackson para que lo ayudase a salir vivo del trance en que se encontraba. Así, el 4 de julio le envió una carta, en la que le relataba los acontecimientos más significativos desde su llegada a Texas, una copia de los Convenios de Velasco, y un ruego mal disimulado:

La continuación de la guerra y sus desastres serán, por consiguiente, inevitables, si una mano poderosa no hace escuchar oportunamente la voz de la razón. Me parece, pues, que usted es quien puede hacer tanto bien a la humanidad, interponiendo sus altos respetos para que se lleven a cabo los citados convenios, que por mi parte serán exactamente cumplidos. ${ }^{23}$

Los meses transcurrían y Andrew Jackson no contestaba la misiva. Pero sí estaba muy pendiente del asunto, como lo demuestra esta comunicación del 4 de septiembre a Samuel Houston, después de haber escuchado rumores de que Santa Anna iba a ser juzgado por una corte y luego fusilado:

Esto sería monstruoso. Nada ahora podría empañar el carácter de Texas más que un acto de esta naturaleza. Fue una buena

${ }^{23}$ Fuentes Mares, Santa Anna, 1982, p. 146.

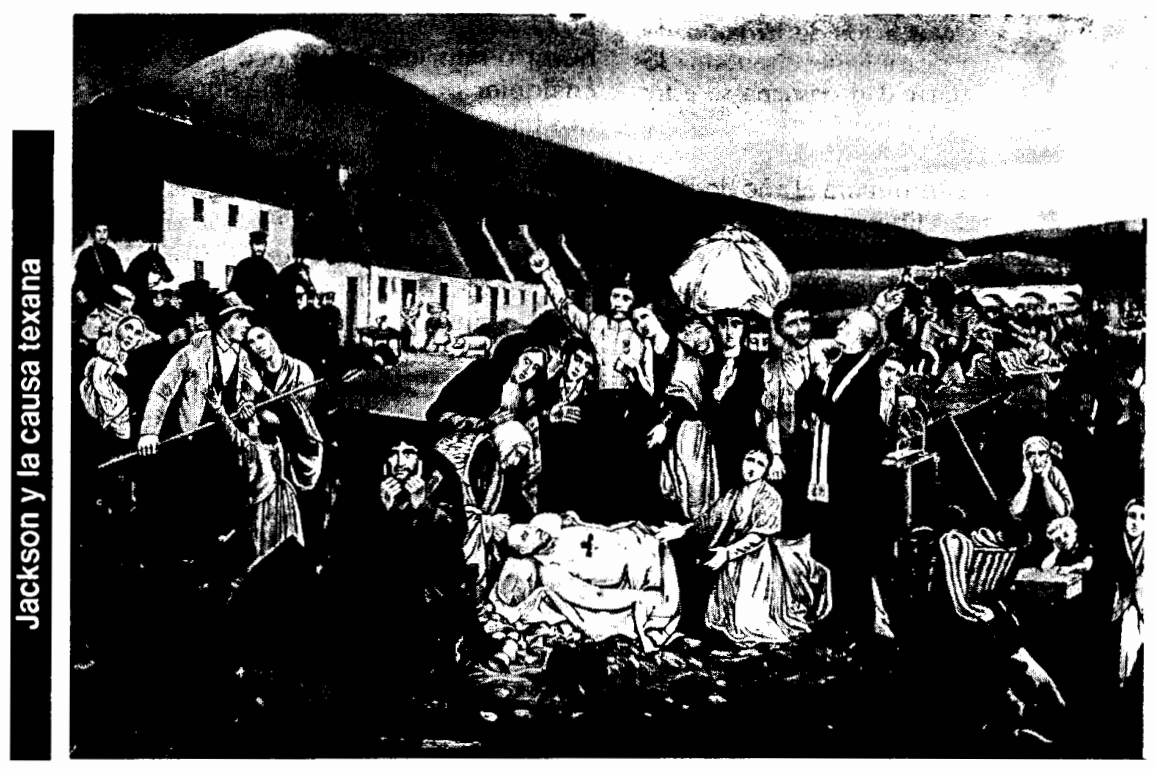


política, así como de humanidad permitirle vivir [...] Su persona es todavía de consecuencias para usted; es el orgullo de los soldados mexicanos y el favorito del clero [...] no deje que su sangre sea derramada a menos que se vuelva necesario por un acto imperativo de justa represalia por las masacres hechas por los mexicanos en el futuro. Esto es lo que yo pienso, y lo que la verdadera cordura y humanidad dicta. ${ }^{24}$

Ese mismo 4 de septiembre llegó una respuesta de Jackson a Santa Anna, en ella lamentaba que no pudiera hacer nada por el comandante mexicano:

Sus poderes cesaron con su captura [...] por lo tanto, hasta que el actual gobiemo de México pida nuestros oficios amigables entre las partes contendientes, México y Texas, no podemos interferir; pero si México lo solicitara, nuestros oficios amigables serian, con placer, aportados para restaurar la paz y poner fin a esta guerra inhumana, cuyos actos de barbaridad y masacre han ocasionado que todos los pueblos y humanidad cristiana se estremezcan y condenen. ${ }^{25}$

Antes de que terminara el año de 1836 , Houston decidió liberar a su prisionero, con la condición de que viajara a Washington y viese al presidente Jackson, esperando de aquí una solución al problema diplomático derivado de la independencia texana. Después de navegar por el río Mississippi y seguir el curso del río Ohio, Santa Anna llegó a la capital de Estados Unidos en medio de una nevisca, el $17 \mathrm{de}$ enero de 1837 . El presidente de los norteamericanos recibió al derrotado con todos los honores propios de un jefe de Estado. Después del banquete oficial, el anfitrión y su huésped se sentaron a dis-

${ }^{24}$ Citado por Remini, Jackson, 1976, p. 361.

${ }^{25}$ Fuentes Mares, Santa Anna, 1982, p. 147. cutir la posibilidad de que ellos elaboraran conjuntamente un tratado que resolviera de una vez por todas el "problema" de Texas. Santa Anna mencionaría que Jackson le ofreció sin rodeos una "indemnización" de 5000000 de dólares si México reconocía la independencia de Texas. Según el veracruzano, le respondió que "solamente correspondía al Congreso mexicano el derecho de decidir sobre esta cuestión". ${ }^{26}$

La versión de Jackson fue diferente. De acuerdo con ella, Santa Anna le propuso la cesión de Texas a cambio de una "justa consideración". El Viejo Roble le respondió que Estados Unidos no podía hacer nada sobre una cesión hasta que se resolviese "la disposición de los texanos". "Hasta que Texas sea reconocido como país independiente", afirmaría el mandatario norteamericano. $Y$ puesto que Santa Anna no estaba facultado para hablar en nombre del gobierno mexicano, "nosotros sólo podemos instruir a nuestro ministro en México para recibir cualquier proposición que su gobiemo nos haga sobre el asunto"; pero Jackson fue todavía más lejos: manifestó a su interlocutor que Estados Unidos estaba interesado en extender su frontera para incluir Texas y el norte de California, de tal manera que la línea divisoria corriera por "la línea de Estados Unidos al río Grande. De allí a la latitud 38 norte y luego al Pacífico para incluir el norte de California." En compensación, ofrecería 31500000 dólares. "Pero antes de prometer nada", continuó Jackson, "el general Santa Anna debe decir que usará su influencia para suspender las hostilidades". Aquî es cuando Santa Anna habría hablado de la responsabilidad del Congreso mexicano para decidir sobre

\footnotetext{
${ }^{26}$ Santa Anna, Eagle, 1967, p. 365.
} 
ese asunto. De cualquier modo, Jackson fue ambiguo cuando sostuvo que "esta proposición está hecha para conocer los puntos de vista del general, y no por Estados Unidos para adquirir el territorio o tomar ventajas del estado de desorden en que México se encuentra" ${ }^{27}$ Es obvio que las versiones de los protagonistas fueron verdades a medias. En todo caso, puede suponerse que las pláticas estaban determinadas por la situación que guardaba el proceso de "americanización" de Texas. Jackson buscaba una "transacción honorable", mientras que Santa Anna buscaba salvar su vida por sobre todas las cosas. La entrevista Jackson-Santa Anna terminó con una nota indefinida y cortés, y luego el mexicano se dirigió a Veracruz a bordo de un buque de guerra de Estados Unidos.

Jackson mencionó esta conversación a William Wharton, el representante texano en Washington. Cuando el presidente le sugirió un posible tratado "político" con México, Wharton protestó airadamente. La independencia de Texas, alcanzada por sus propios medios militares, era un hecho consumado. Negó en su totalidad el derecho de México a vender Texas o a hacer un tratado que comprometiese a Texas sin su anuencia. Ante tal situación, Jackson admitió como válidos los argumentos de Wharton y juró que "antes perecería que ser culpable de cualquier injusticia contra Texas o de comprometerla sin su consentimiento". Wharton replicó que era "verdaderamente humillante" que Texasfuera vendida aun en forma nominal, después de todas las que había pasado para lograr su independencia. Jackson asintió, pero "la herida al orgullo (de Texas) era sólo en nombre...no en sustancia". El repre-

${ }^{27}$ Remini, Jackson, 1976, p. 365. sentante texano insistió en que el reconocimiento de la independencia de Texas por Estados Unidos debía ser la condición para cualquier tratado. Y este imperativoera primordial. Sólo entonces Texas podría ser un igual. El reconocimiento debía ser logrado en el Congreso, pues de lo contrario los texanos juzgarían un rechazo "como una evidencia de la frialdad e iliberalidad, por no decir injusticia", de parte de la administración de Jackson. ${ }^{28}$

El deseo de los texanos de ser ciudadanos de Estados Unidos crecía en la medida en que los ciudadanos de este país expresaban con una fuerza cada vez mayor su apoyo a la nueva república. Estas circunstancias pesaban demasiado en el ánimo del presidente Jackson. Durante la segunda semana de febrero de 1837, el Viejo Roble se entrevistó con Wharton y otros representantes oficiosos de Texas. El presidente, de manera inesperada, hizo el anuncio de su deseo por un reconocimiento inmediato de la independencia de Texas, pero por razones de forma el Congreso debía tomar la iniciativa y aparecer como responsable principal. Éste respondió a los deseos de todos los negociadores del reconocimiento, y el 28 de febrero la Cámara de Representantes aprobó una serie de resoluciones por medio de las cuales se autorizaban los fondos necesarios para el reconocimiento formal y el nombramiento de un agente ante el gobierno texano. Al día siguiente, el 1 de marzo, el Senado recomendó al presidente el reconocimiento formal de Texas. ${ }^{29}$ Dos dias después, y antes de concluir su administración, Jackson citó a los representantes texanos en la Casa Blanca. Les anunció que había "consumado" el reco-

${ }^{28}$ Ibid., p. 365.

${ }^{29}$ Pletcher, Diplomacy, 1975, pp. 72-73. 
nocimiento del Senado y la autorización para nombrar a Alceé Labranche como encargado de negocios en la República de Texas. Esta nominación ya había sido enviada al Senado, que la refrendó de inmediato. Jackson caballerosamente pidió a sus invitados que se le unieran para chocar los vasos de vino con un brindis: ¡Texas $!^{30} \mathrm{El}$ reconocimiento causaría una verdadera conmoción entre los mexicanos, que no esperaban que llegase tan pronto, dadas las protestas de prudencia y neutralidad de parte de Jackson.

Este acto político-diplomático fue el último llevado a cabo por Andrew Jackson en materia de política exterior. En ese mismo año de 1837 fue sucedido por Martin van Buren, demócrata del norte y anterior vicepresidente de Estados Unidos. Se retiró a su finca Hermitage, y desde allí siguió observando e influyendo sobre el partido al que pertenecía. En adelante, y hasta las vísperas de su fallecimiento, haría valer su enorme peso político y su prestigio en favor de la anexión de Texas. Es válido afirmar que la participación del ex presidente Jackson en los entretelones del poder fue determinante en los acontecimientos que culminarían con el agregamiento de la estrella solitaria a Estados Unidos. Un día, mientras se recuperaba de su última "sangria", fue visitado por un joven llamado William D. Miller, secretario privado del general Sam Houston, presidente de la república de Texas. Llevaba una carta para el Viejo Roble, escrita por su jefe. Era una respuesta a otra que Jackson le había escrito meses atrás, y en ella Houston manifestaba su voluntad de cooperar

\footnotetext{
${ }^{30}$ Remini, Jackson, 1976, p. 368. Otros detalles sobre el reconocimiento se encuentran en Latner, "Andrew", 1984, p. 145.
}

para la anexión inmediata de Texas a Estados Unidos.

Jackson siempre había deseado la anexión de Texas, no obstante su actitud durante los últimos años de su periodo presidencial. Era parte de su eterno sueño de extender su nación hacia lo que era la América española. Como antes a la Florida, consideraba a Texas una amenaza contra Estados Unidos si era dominada por potencias extranjeras. Ahora estaba más convencido que nunca de que la anexión de Texas era una verdadera garantía para la paz de su nación. "La seguridad de la república es ley suprema, y Texas nos ofrece la llave de la seguridad para nuestro país, de toda la diplomacia y las intrigas foráneas", escribiría el Viejo Roble a Blair. "Yo acepto la llave...y cierro la puerta de inmediato." Y Jackson no desaprovechó la oportunidad para difundir sus ideas al respecto.

A la carta que Thomas W. Gilmen escribió al diario baltimorense The Republican en 1843, demandando la anexión de Texas, dado el "creciente interés" de la Gran Bretaña por la estrella solitaria, el Viejo Roble contestó en términos muy favorables. Insistía en que Texas pertenecía a Estados Unidos en virtud del tratado de compra de la Luisiana, pero había sido "vergonzosamente cedida" por John Quincy Adams en el tratado con Onís. También declaró que si la Gran Bretaña se alzaba con Texas independiente, aquella potencia europea podía movilizar entonces

un ejército de Canady (Canadá) a lo largo de nuestra frontera occidental, marchar a través de Arkansas y Luisiana, capturar Nueva Orleans, excitar a los negros para que se levanten, enviar a los indios del oeste a la guerra, y echar todo nuestro oeste a las llamas, que costaría océanos de 
sangre y cientos de millones de dinero para apagarlos y recuperarnos [...] Texas debe ser nuestra; nuestra seguridad lo requiere. $^{31}$

Los imaginados designios británicos sobre Texas iban a ser argumentos de fuste para la anexión de la otrora provincia mexicana. Tan pronto como Calhoun tomó el puesto de secretario de Estado durante la presidencia de John Tyler (1841-1845), Jackson le llamó la atención sobre la necesidad de adquirir Texas, en términos de neutralizar las iniciativas de la Gran Bretaña:

El actual momento, propicio para obtener Texas, no debe perderse, pues de otro modo Texas necesariamente se vería arrojada en brazos de Inglaterra, y la perdería para siempre Estados Unidos..$^{32}$

El Viejo Roble continuó diciéndole que si la Gran Bretaña dominaba Texas, ella pondría su fuerza para detener la emigración de norteamericanos a California. Para él no quedaba ninguna duda de que Texas y California eran las dos partes de un mismo proceso.

La "amenaza británica", en realidad, estaba muy lejos de serlo. A partir de su última guerra con Estados Unidos (1812), Londres perdió interés en la posesión de más territorios en Norteamérica. A pesar de que su imperio seguía creciendo en otras partes del mundo, ya mostraba una relativa indiferencia por las tierras americanas. La política británica más bien respondía a sus necesidades comerciales, reservando su ejército y marina para apoyar al capital en expansión. Estados Unidos, en cambio, hacía descansar su poderío en la posesión de espacios geográficos. La postura de Londres sobre

${ }^{31}$ Citado por Remini, Jackson, 1976, p. 492.

${ }^{32}$ Price, Origenes, 1967, p. 145.
Texas no tenía nada que ver con las especulaciones que circulaban en el ambiente temeroso de Estados Unidos. Gran Bretaña protestaba una y otra vez su política de no intervención en Texas, y su papel se reducía a intentar la mediación entre Texas independiente $y$ México a fin de que pudieran resolver sus diferencias y vivir en paz. Aun cuando Londres se proclamaba campeona del abolicionismo, afirmaba no buscar influir en más de una manera "moral" para acabar con la esclavitud. Todos los hechos de la época parecen indicar, en definitiva, que las intenciones británicas estaban muy lejos de ser como las describian los expansionistas norteamericanos. El presidente John Tyler estaba ansioso por llevar a cabo la anexión de Texas, pero la situación no era sencilla. En su mayoría, el norte se oponía a que existiera un estado esclavista más rompiendo así el precario equilibrio políticoregional que se había logrado hasta entonces. Preocupación secundaria era una eventual guerra con México por esta causa, dada la confianza que en ella misma tenía la Unión Americana de derrotar a su vecino, y la posibilidad de arrebatarle todavía más territorios. Tyler resolvió acudir al ex presidente Jackson para que volcara su peso e influencia política para lograr la anexión texana. La tarea de acercarse a Jackson fue encomendada al senador Robert Walker, de Mississippi. "Le escribo confidencialmente y con prisa", decía en una carta al viejo general. "Pienso que la anexión de Texas depende de usted. Éste sería un acto supremo que coronaría su actuación política." Más adelante señalaría:

Parece que Houston pensaba que un tratado de anexión hecho por el gobierno actual fracasaría porque los demócratas votarían contra él. ¿Podría usted escribir a 


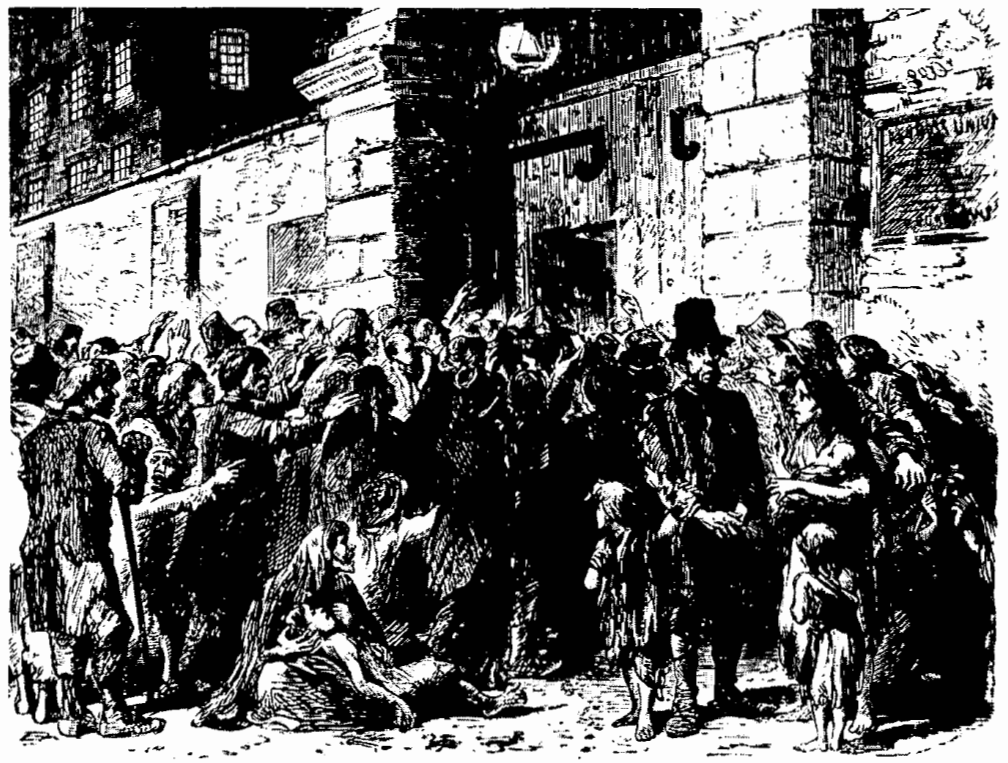

Houston y hacerle cambiar de opinión?...Cualquier retraso en el proceso de anexión podria hacer que Texas se perdiera para siempre. ${ }^{33}$

Jackson aceptó cooperar. Escribió varias cartas a Houston en enero de 1844 , en las que predijo que si la anexión fuese exitosa "su nombre y fama estarían en el altar de los grandes capitanes de la historia". También le envió la carta de Walker, y le hizo notar "qué optimista" era Walker acerca de las posibilidades de la anexión. "Usted sabe que puede confiar en mi amistad y yo le digo a usted que tal tratado, hecho bajo su administración, hará más por la prosperidad y felicidad permanente de Texas [...] que cualquier otro acto de su vida."

La respuesta de Houston llegó dos

\footnotetext{
${ }^{33}$ Remini, Jackson, 1976, p. 493.
}

meses después. El presidente texano manifestó su "éxito" en los tratos con las potencias europeas, particularmente con la Gran Bretaña. Y sentenció: "Texas en paz puede existir sin Estados Unidos, pero Estados Unidos no puede, sin gran peligro para su seguridad, existir sin Texas." De cualquier modo, Houston resaltó la importancia de Estados Unidos, y anunció a Jackson que un ministro especial se abocaría "a considerar el trabajo de la anexión". El vencedor de San Jacinto, sin embargo, advirtió que si el proceso de ratificación fallaba en el Sęnado norteamericano, Texas buscaría "algún otro amigo" en la familia de naciones. ${ }^{34}$ Houston sabía que agitar el fantasma de una alianza texano-británica podría punzar el ánimo de los políticos de Washington. Por lo demás, era una realidad que lo

${ }^{34}$ Davis, Old, 1977 , pp. 375-376. 
que a Texas convenía era anexarse a Estados Unidos, más que buscar amistades que a la postre le serían fuente de problemas con su poderoso vecino norteamericano.

La campaña por la anexión de Texas había estado marcada por el fracaso constante desde que los texanos habían hecho patentesudeseode unirse a Estados Unidos en la época del presidente Jackson. Ellos habían sido rechazados una y otra vez. El asunto quedó empantanado hasta que el presidente John Tyler le dio una nueva vitalidad. Éste era un sureño, simpatizante del anexionista Calhoun, y un mandatario en busca desesperada de alguna causa que le diera la reelección. Por lo demás, había mostrado interés en adquirir Texas tan pronto como entró a la Casa Blanca. Gracias a su iniciativa, en abril de 1844 fue firmado un tratado de anexión entre los representantes de Texas y de Estados Unidos. Casi inmediatamente, Tyler envió las buenas nuevas a Jackson. Diez días despuéssesometía el documentoalSenado para su ratificación, pero contrariamente a lo que se esperaba fue derrotado. Cuando el proyecto de tratado fue enviado a esta instancia legislativa, se lo acompañó de una extraña carta escrita por el secretario de Estado Calhoun al ministro británico Richard Pakenham, en la que se tocaba el delicado tema de la esclavitud. Argumentaba que el convenio de anexión tenía como propósito principal proteger a la esclavitud en Estados Unidos contra los esfuerzos británicos, ya que suintervención en Texas era parte de su campaña por la abolición universal. Así, las iniciativas norteamericanas se dirigían a bloquear ese "censurable esfuerzo". Resulta a las claras que Calhoun, por oscuros motivos, puso en la base de la anexión preservar la esclavitud en Estados Unidos, lo que levantó ámpula en los demócratas del norte y desde luego en Andrew Jackson.
Para mala fortuna de la causa expansionista, las posiciones sobre la anexión de Texas se radicalizaban cada vez más, y se manifestaban con fuerza ante las elecciones presidenciales venideras. EI 27 de abril de 1844 el washingtoniano National Intelligencer publicó una carta escrita por el whig Henry Clay, en la que este candidato se oponía decididamente a la adquisición de Texas. Consideraba que sería peligrosa para el país porque podría ocasionar una guerra con México, excitar pasiones en torno a la esclavitud dentro de la Unión, y resultaria un desastre financiero, porque la deuda texana de alrededor de 10000000 de dólares tendría que ser absorbida por Estados Unidos. De consecuencias aún mayores fue una misiva escrita por Van Buren, demócrata del norte y seguro candidato a la presidencia, aparecida en The Globe el mismo día en que se publicó la carta de Clay. Puesto que ambos esperaban evitar que el tema de Texas apareciese en las elecciones, puede asumirse que existió un acuerdo previo entre los contendientes. Van Buren confesó sin rodeos su oposición a la anexión, por considerar que provocaría rencores seccionales y una posible guerra con México. Pero, añadió que si el pueblo favorecía la anexión, él accedería a sus deseos y marcharía con ellos. "Otras naciones pueden recurrir a la agresión y a la conquista", declaró, "pero esta nación se regula por la razón y la justicia". ${ }^{35}$

El Viejo Roble se consternó al leer la carta de Van Buren. Temeroso de que la eventual elección de este neoyorkino como candidato demócrata a la presidencia pudiera dividir al partido, Jackson se apresuró a hacerle saber que, en vista de su oposición a la anexión de Texas "sería imposible elegirle, como imposible

${ }^{35}$ Remini, Jackson, 1976, p. 496.

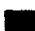


sería desviar el curso del Mississippi" ${ }^{36}$ Ante esta situación, ¿a quién elegirían los demócratas en su lugar? Tyler, el presidente sin partido, estaba descartado; Calhoun era mencionado por algunos demócratas sureños, pero para muchos otros, especialmente del norte, no podría ser. Otras posibilidades incluyeron a Lewis Cass, James Buchanan, Richard Johnson, Levi Woodbury, y Thomas Hart Benton. Este último personaje era de singular relieve, pero también habia juzgado al tratado de anexión como un criminal intento de desmembrar a México. Silas Wright Jr., de Nueva York, se negó a la nominación debido a su lealtad a Van Buren. El único que le quedó al Viejo Roble fue James K. Polk, de Tennessee, un político de lealtad probada pero carente de brillo. Después de mucho pensarlo y consultarlo con sus más cercanos aliados políticos, decidió invitar a Polk al Hermitage, el 12 de mayo de 1844. Mantuvo con él una amplia conversación, en la que mencionó que Van Buren y Benton "se habían cortado políticamente sus propias gargantas". "El candidato para el primer puesto", diría con voz fuerte, "debe ser usted!", dirigiendo su indice a James Polk. ${ }^{37}$ ¿Por qué Jackson se había inclinado por un hombre relativamente desconocido como el siguiente candidato presidencial por el Partido Demócrata? El Viejo Roble consideraba que los demás posibles candidatos tenían limitaciones insalvables de un tipo o de otro. Ninguno de ellos podría mantener unido al partido. Muchos de ellos lo distraerían, excitarian las pasiones y los antagonismos, y conducirían a una guerra civil interna. Polkera partidario de las políticas y los principios que Jackson había sostenido a lo largo de sus ocho

\footnotetext{
${ }^{36}$ Ibid., pp. 498-499.

${ }^{37}$ Ibid., p. 501.
}

años como presidente. Y lo que es más importante: era un anexionista, y además provenía del suroeste.

Las cosas salieron como Jackson las había planeado. En la tormentosa Convención Demócrata de Baltimore que dio principio en mayo de ese año, James Polk y George Dallas resultaron electos a la presidencia y a la vicepresidencia, respectivamente, con la bandera de “¡Polk y Dallas, Oregon y Texas!". Polk sería presentado ante los votantes como "Young Hickory", el heredero de la ideología y la política jacksonianas. Éste, por su parte, estaba en contacto estrecho con su patrocinador, solicitándole consejos y apoyos desde entonces hasta su victoria electoral. Entre las peticiones que le hizo fue pedirle que escribiera a Houston y le urgiera a "soportar la presión europea" para entrar en una alianza en virtud de la cual EU garantizaría la independencia de Texas. Durante ese tiempo, Houston aparentemente evitaba comprometerse con Jackson, ya que no sabía a ciencia cierta cuál debía ser su siguiente movimiento. Deseaba mantenerse libre de ataduras para el caso de que Texas optase por la independencia nacional. ${ }^{38}$

Aunque Jackson tuvo un éxito total al lograr que su protegido Polk fuese nominado candidato presidencial demócrata, fracasó en su intento de derrotar a los enemigos de la anexión en el Senado. El 8 de junio, sin que nadie se sorprendiera, esta cámara rechazó el tratado de Texas por 35 votos contra 16, gracias a la alianza de los whigs y los demócratas leales a Van Buren. La responsabilidad de esta derrota cayó en Calhoun, debido a la famosa carta dirigida a Pakenham. En cuanto se enteró de este suceso, el Viejo Roble se dirigió a

$$
{ }^{38} \text { Ibid., p. } 506 .
$$


Houston, a quien comunicó que estaba preparado para impedir la pérdida de Texas, que sentía amenazante para la seguridad nacional y que conduciría a una guerra. En cuanto a Polk, Jackson le urgió a mantener vivo el asunto de la anexión. "Fustiga a Clay (el candidato whig) sobre Texas", era el principal consejo que le daba el Viejo Roble a su pupilo. Tyler también le pidió a Jackson más ayuda en el asunto de Texas. El representante norteamericano en la república de la estrella solitaria había muerto, y el presidente nombró a Andrew J. Donelson (hijo de Jackson) en su lugar. Aparte de sus habilidades, Donelsonera el escogido, no solamente porque conocía personalmente a Houston, sino porque era miembro de su familia.

En noviembre de 1844 James K. Polk ganaría las elecciones presidenciales por un margen electoral de 65 votos, y una mayoría popular de escasos 38000 votos de un padrón de 2.6 millones de ciudadanos. ${ }^{39}$ Polk visitó el Hermitage de inmediato. Una vez ahí, el Viejo Roble le predijo que el Congreso pasaría una resolución favorable sobre Texas. Poco antes había pedido a Sam Houston que "resistiera las lisonjas de los británicos", y el texano le respondió que así lo haría. ${ }^{40}$

Andrew Jackson no descansaría mientras que el asunto de Texas no se resolviera conforme a sus deseos. Una vez que el Congreso se volvió a reunir en diciembre, el general abrumó a sus partidarios con demandas de que aprobaran una resolución cameral conjunta de anexión inmediata y así ejecutaran "la voluntad del pueblo como había sido expresada en la elección de Polk". Esta vez las cosas resultaron de otro modo. En

\footnotetext{
${ }^{39}$ Davis, Old, 1977, p. 378.

${ }^{40}$ Ibid., p. 379.
}

la sesión cameral que dio inicio el 2 de diciembre de 1844 se dio a conocer la iniciativa del presidente Tyler para que se adoptara una resolución bicameral para la anexión de Texas. Este procedimiento se impuso porque la única posibilidad constitucional para aprobar el tratado era con los votos de la mayoría simple de los miembros de las dos cámaras legislativas. El otro camino, el de la aprobación senatorial (que por lo demás requería del voto mayoritario de las dos terceras partes de la asamblea), ya se había probado sin éxito. Así, para el 1 de marzo de 1845, tres días antes de dejar su puesto, Tyler firmó el documento que consagraba la anexión de Texas a Estados Unidos. La suerte estaba echada.

¿Cuál fue la respuesta de Texas ante los acontecimientos de la anexión? En la víspera, las posiciones de su sociedad estaban divididas. La dureza de la situación por la que atravesaba, el miedo a reanudar las hostilidades con México, y los innumerables lazos personales y económicos con Estados Unidos habían hecho a la mayoría de los texanos partidarios de la anexión. Mas también se había formado una suerte de orgullo nacional; las incertidumbres sufridas hicieron que un número indeterminado de ciudadanos contemplara a la Gran Bretaña como la mejor posibilidad de alianza. No obstante, cuando el asunto se sometió a la votación del Congreso de Texas el 18 de junio de 1845 , el voto fue unánime en favor de la anexión.

En las vísperas del histórico acontecimiento, circularon con fuerza las versiones de que el presidente texano, en ese momento el doctor Anson Jones, se oponía a la anexión y prefería hacer de Texas un cercano aliado de la Gran Bretaña. Sus opositores lo acusaron de querer conservar a su país como nación independiente, y de apoyarse en el capitán 
Charles Elliot -chargé d'affaires de la Gran Bretaña en Texas- para llevar a cabo tal propósito. En realidad, tanto Elliot como el encargado de negocios francés, conde de Saligny, realizaron esfuerzos conjuntos para persuadir al gobierno de Texas de hacer un acuerdo final con México con la esperanza de que la anexión a Estados Unidos fuese descartada. Tanto Gran Bretaña como Francia mantenían en ese momento que un Texas independiente era más ventajoso para sus intereses naciónales desde el punto de vista comercial, especialmente como fuente de algodón, que si fuera parte de Estados Unidos. Estas naciones, por lo tanto, ofrecieron generosamente sus servicios como mediadoras en un intento de restaurar relaciones amigables entre México y Texas sobre la base del reconocimiento mexicano. A fines de marzo, el capitán Elliot había persuadido a las autoridades texanas de emprender negociaciones con México sobre las bases siguientes:

1. Que México debería proponer de inmediato el reconocimiento de la independencia completa de Texas. 2. Que Texas, por su parte deberá en ese caso estipular en un tratado que nunca se anexaría o estaría sujeto a cualquier país. 3. Que la cuestión de los límites y la de indemnización por cualquier porción de territorio debía negociarse, y si surgiesen disputas o dificultades en las negociaciones, éstas deberían someterse al arbitraje. $^{41}$

Elliot se dio cuenta de que era necesario acelerar los acuerdos entre Texas y México. Jones pensaba igual, con el reservado propósito de dejar abiertas tanto la anexión a Estados Unidos como

\footnotetext{
${ }^{41}$ Pletcher, Diplomacy, 1975, pp. 142-149.
}

la independencia y reconocimiento por México. Otra razón para esta prisa, como lo observó Elliot, era que el encargado de negocios norteamericano, mayor A. J. Donelson, era esperado en Texas en cualquier momento, y su presencia daría un estímulo renovado a los anexionistas. El 4 de junio de 1845 el presidente Jones lanzó su proclama de paz entre Texas y México, basada sobre el tratado preliminar y condicional de paz propuesto por Elliot, que ya se había negociado con el gobierno mexicano. ${ }^{42} \mathrm{Un}$ mes después, el 5 de julio, los miembros del Congreso texano aprobaron dos resoluciones, una aceptando las propuestas norteamericanas de anexión y otra rechazando el tratado propuesto con México. Con estos actos, se cerraba el telón para el futuro de Texas como república independiente.

El presidente Anson Jones había manejado hábilmente y con ambigüedad el asunto, con la aprobación de su protector Samuel Houston. Varios años después, se quejó de las ofensas que había recibido por "su supuesta oposición a la anexión" y afirmó que "él había sido autor de la anexión y había trabajado diligente, fiel, celosa y eficientemente para conseguirla, hasta que al fin la había logrado". Jones parecía mostrarse poco entusiasta ante la anexión en 1845, pero en realidad él y Houston buscaban lograr mejores términos de anexión a Estados Unidos. ${ }^{43}$ En su momento, ambos personajes explotarian con provecho los esfuerzos mediadores de los británicos, que desde la independencia de Texas no habían dado ningún paso que comprometiera su neutralidad. Como ya sabemos, lo que perseguían con mayor interés era que Texas se mantuviera indepen-

\footnotetext{
${ }^{42}$ Price, Origenes, 1967, p. 204.

${ }^{43} \mathrm{Jbid}$., p. 166.
} 
diente y en paz con su vecino del sur. Una vez que se dio la anexión de esta república a Estados Unidos, Londres cuidó de què sus relaciones con Washington fuesen de la mayor corrección posible. ${ }^{44}$

A los diez días de que Estados Unidos resolviera sobre la anexión definitiva de Texas, el Viejo Roble diría:

no sólo me regocijo, sino que me congratulo con mi amado país porque Texas ha sido reanexado [...] la seguridad, prosperidad y el gran interés de la Unión serán asegurados por este [...] grande e importante acto nacional. ${ }^{45}$

${ }^{44}$ Las líneas fundamentales de la política británica hacia Texas, en el sentido señalado, se encuentran en Bosch Garcia, Historia, 1985, pp. 158-177.

4s Remini, Jackson, 1976, p. 511.
Su muerte estaba muy cercana. Con esa obsesión por Texas que nunca lo abandonó, llegó a decir: "Al fin todo está seguro." Su viejo amigo (Houston) había "recobrado" Texas para la Unión. Confiaba en que Polk protegería los derechos del país sobre Oregon, y esperaba que fuese sin guerra, y "si no, dejemos que llegue. Habrá suficientes patriotas para repeler la invasión extranjera I. . . " ${ }^{46}$ El domingo 6 de junio de 1845 expiraba tranquilamente en el Hermitage. Sam Houston no alcanzó a despedirse de su jefe y amigo. Llegó horas después de que el Viejo Roble había dejado de existir. Acompañado de su hijo, entró a la habitación en la que se le velaba, se acercó al cadáver, y Houston, inflamado por un espíritu de grandeza, diría: "hijo mio, trata de recordar siempre que tú miraste

${ }^{46}$ Davis, Old, 1977, p. 511.

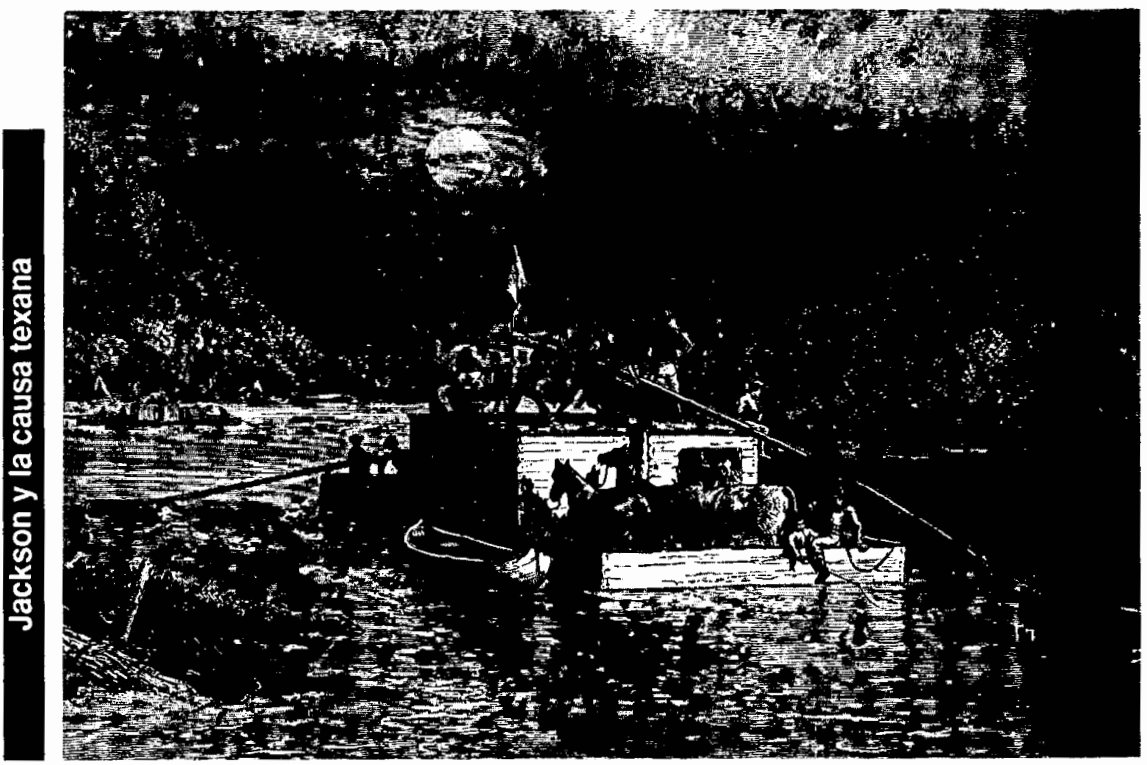


la cara de Andrew Jackson". Después de todo, el difunto también era padre de Texas.

El asunto texano fue ocasión ejemplar de la forma en que Andrew Jackson demostraría su infatigable determinación y fuerza de voluntad. A lo largo de su existencia Texas fue uno de sus motivos vitales, y no descansó hasta ver realizados sus propósitos. Su cualidad de estadista le permitió poner su impronta en los acontecimientos nacionales en que le tocó participar. Por lo demás, está fuera de discusión su papel de autor intelectual del proceso que se inició con una rebelión de colonos y culminó con la anexión de nuevos territorios a Estados Unidos.

Uno de los aspectos más interesantes del tema que tratamos es la actividad conspirativa de Jackson para lograr la adquisición de Texas. El Viejo Roble era oriundo de Tennessee, estado fronterizo con una larga experiencia en luchas indias y una vocación esclavista. Su idea de que Estados Unidos debía crecer hacia el oeste estaba mucho más arraigada que en el resto de los estados de la Unión. El triángulo formado por Andrew Jackson, Samuel Houston y James Polk encarnaba sin reservas esos atributos de su tierra nativa. Es idea fundamental de este ensayo que el expansionismo norteamericano, más que haber sido resultado de la operación de fuerzas ciegas ubicadas en la economía o la política, fue fruto de la áctividad de un grupo dirigente bajo el liderazgo de Jackson. Esta idea queda confirmada por el hecho de que los principales artífices del crecimiento territorial en una parte del siglo $\mathrm{xIX}$-Samuel Houston, James K. Polkfueron sus amigos y colaboradores políticos hasta el final de sus vidas.

La expansión de Estados Unidos, desde un punto de vista estrictamente políti- co, no podia ser más popular: significaba espacios "nuevos" para la agricultura, la industria y el comercio, así como la posibilidad de ganancias rápidas para los especuladores de tierra y la confirmación del "destino manifiesto" de los norteamericanos. Este proceso, por lo demás, era congruente con un estilo exaltado de hacer política, inaugurado precisamente por Jackson. Frente a las crisis económicas que asolaron a Estados Unidos durante las primeras décadas del siglo pasado, la esperanza de nuevos territorios servía como válvula de escape a la frustración social y era un instrumento que fortalecía al llamado "populismo jacksoniano". La habilidad de Jackson y los suyos para interpretar este sentimiento colectivo y vincularlo con sus prédicas "democráticas", sería pasto para el fuego de las conquistas imperiales. Pero éstas no estaban exentas de riesgo para la supervivencia misma de la nación.

Jackson ejerció la presidencia mientras que el conflicto seccional iba en callado ascenso. Más que cualquier otro político de su tiempo, el Viejo Roble comprendió los peligros y supo maniobrar en aguas turbulentas. Con habilidad aquietó las primeras manifestaciones del antagonismo, e impidió que el asunto de la esclavitud pudriera la vida política durante su administración. Es de notar que Jackson mantuvo, en un momento delicado, el equilibrio nacional frente al espinoso asunto de Texas. A pesar de los riesgos involucrados, fue actor en la transición territorial de su país, sin liberar el potencial explosivo de un conflicto que se incubaba sin remedio. Consciente de que la anexión de Texas provocaría por necesidad un desequilibrio entre los intereses regionales, se negaría una y otra vez a presentar la incorporación texana como un triunfo de algún grupo particular. 


\section{SECUENCIA}
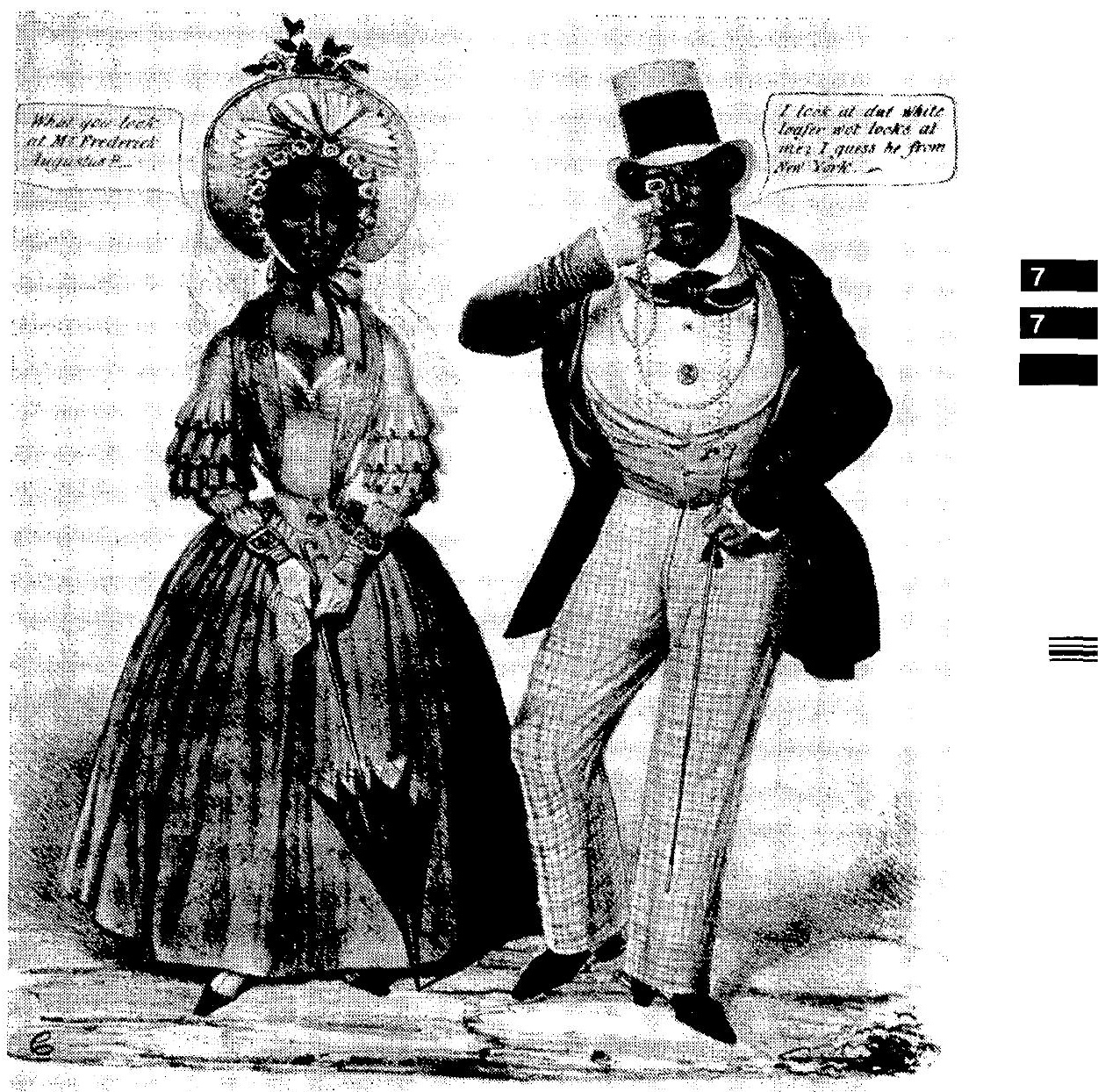

PHITIAADELIPHIA PASITIDNS, 1837 . 
Los ideales expansionistas de Jackson sobrevivieron a su muerte. Con miras a restablecer la armonía nacional, sus sucesores pugnaron por llevar a cabo sus recomendaciones: la paz exigía la satisfacción de los intereses del norte, y ella solamente llegaría a través de la adquisición de la Alta California. Esta consigna fue seguida con celo jacksoniano, y a James Polk tocaría realizar los añorados proyectos de su jefe. A la postre, el precario equilibrio del país se rompió, pero una vez que la continentalización había sido por fin alcanzada. En adelante, la conquista de territorios "nuevos" perdería impulso, y con ella, la quimera de que Estados Unidos empezara en el polo norte y terminara en la Tierra del Fuego.

\section{BIBLIOGRAFÍA}

-Bassett, John, The life of Andrew Jackson, Archon Books, Hamden, 1967.

-Bosch Garcia, Carlos, Historia de las re. laciones entre Méxicoy Estados Unidos, 1819. 1858, Secretaría de Relaciones Exteriores, México, 1985.

-Daniels, Jonathan, Ordeal of ambitions. Jefferson. Hamilton. Burr, Doubleday, Garden City, 1976.

-Davis, Burke, Old Hickory: a life of Andrew Jackson, Dial Press, Nueva York, 1977.

-Fuentes Mares, José, Santa Anna: el bombre, Editorial Grijalbo, México, 1982.

-Hietala, Thomas, Manifest design: anxious aggrandezement in late jacksonian
America, Cornell University Press, Ithaca, 1985.

-James, Marquis, The raven: a biograpby of Sam Houston, Blue Ribbon Books, Inc., Nueva York, 1929.

-Latner, Richard B., "Andrew Jackson", The presidentes: a reference bistory, Charles Scribner's Sons, Nueva York, 1984.

-Merk, Frederick, Manifest Destiny and mission in American bistory: a reinterpretation, Knopf, Nueva York, 1963.

-Moyano Pahissa, Ángela, México y Estados Unidos: origen de una relación, 18191861, SEP, México, 1987.

-Padover, Saul K., Jefferson: un paladin de la independencia de los Estados Unidos de América, Compañía General Editora, Buenos Aires, 1969.

-Price, Glenn, Origenes de la guerra con México, FCE, México, 1967.

-Pletcher, David M., The diplomacy of an nexation: Texas, Oregon and the mexican war, University of Missouri Press, Missouri, 1975.

-Remini, Robert V., Andrew Jackson and the course of the american democracy 18331845, Harper and Row, Nueva York, 1976.

-Rives, George Lockhart, "Mexican diplomacy on the eve of the war with the United States", American History Review, núm. 8, enero de 1913.

-Santa Anna, Antonio López de, The eagle: the autobiograpby of Santa Anna, Pemberton, Austin, 1967.

-Stenberg, Richard R., "The Texas schemes of Jackson and Houston", Soutbwestern SocialScience Quarterly, núm. 15, diciembre de 1934. 